\title{
A Computational Approach to Mechanistic and Predictive Toxicology of Pesticides
}

\author{
Kristine Kongsbak ${ }^{1,2}$, Anne Marie Vinggaard ${ }^{2}$, Niels Hadrup ${ }^{2}$, and Karine Audouze ${ }^{1}$ \\ ${ }^{1}$ Center for Biological Sequence Analysis, Department of Systems Biology, Technical University of Denmark, Kongens Lyngby, \\ Denmark; ${ }^{2}$ Division of Toxicology and Risk Assessment, National Food Institute, Technical University of Denmark, Søborg, \\ Denmark
}

\begin{abstract}
Summary
Emerging challenges of managing and interpreting large amounts of complex biological data have given rise to the growing field of computational biology. We investigated the applicability of an integrated systems toxicology approach on five selected pesticides to get an overview of their modes of action in humans, to group them according to their modes of action, and to hypothesize on their potential effects on human health.

We extracted human proteins associated with prochloraz, tebuconazole, epoxiconazole, procymidone, and mancozeb and enriched each protein set by using a high confidence human protein interactome. Then we explored modes of action of the chemicals by integrating protein-disease information into the resulting protein networks. The dominating resulting human adverse effects were reproductive disorders followed by adrenal diseases.

Our results indicated that prochloraz, tebuconazole, and procymidone exert their effects mainly via interference with steroidogenesis and nuclear receptors. Prochloraz was associated with a large number of human diseases and, together with tebuconazole, showed several significant associations with testicular dysgenesis syndrome. Mancozeb showed a differential mode of action involving inflammatory processes. This method provides an efficient way of overviewing data and grouping chemicals according to their mode of action and potential human adverse effects. Such information is valuable when dealing with predictions of mixture effects of chemicals and may contribute to the development of adverse outcome pathways.
\end{abstract}

Keywords: computational tool, pesticides, grouping, systems biology, testicular dysgenesis syndrome

\section{Introduction'}

Increasing evidence shows that adverse human health effects like male and female reproductive disorders are increasing. Around $8 \%$ of all children are currently conceived by in vitro fertilization and up to $9 \%$ of newborn boys are born with malformed reproductive organs like cryptorchidism in Denmark (Wohlfahrt-Veje et al., 2009). Chemical exposure may contribute to the increasing prevalence of these health disorders (Wohlfahrt-Veje et al., 2009; Weidner et al., 1998; Swan et al., 2005). Previous epidemiological research has indicated associations between pesticide exposure and endocrine disruption leading to, e.g., poor semen quality (Swan et al., 2003) and increased incidence of cryptorchidism (Weidner et al., 1998; Damgaard et al., 2006).
Other studies have shown the simultaneous occurrence of various endocrine active chemicals in human body fluids, such as urine (Swan et al., 2005) and breast milk (Damgaard et al., 2006; Krysiak-Baltyn et al., 2012). These findings have been correlated with incidences of malformed reproductive organs such as decreased anogenital distance and cryptorchidism in boys of exposed mothers, respectively. These epidemiological studies indicate that prenatal chemical exposure might be a risk factor for congenital reproductive abnormalities. Experimental studies have shown that mixtures of chemicals can result in substantial effects on various endpoints in spite of doses of the individual chemicals being too low to exert effects on their own. This has been demonstrated both in vitro (Rajapakse et al., 2002; Silva et al., 2002) and in vivo (Hass et al., 2007, 2012; Metzdorff et al., 2007; Christiansen et al., 2008, 2009; Jacobsen

Received April 24, 2013; accepted in revised form September 6, 2013; Epub September 17, 2013; http://dx.doi.org/10.14573/altex.1304241

1 Abbreviations: CTD, Comparative Toxicogenomics Database; CYP, cytochrome P450; ODS, ovarian dysgenesis syndrome;

OMIM, Online Mendelian Inheritance in Man; PPI, protein-protein interaction; TDS, testicular dysgenesis syndrome 
et al., 2012). It is often a challenge within epidemiological research to find significant associations between human diseases and exposure to single chemicals. This may be partly due to the fact that humans are seldom exposed to one single chemical at a given time point, but are most likely exposed to complex mixtures of chemicals (Krysiak-Baltyn et al., 2010).

Today's toxicologists are facing several challenges. One challenge is how to handle risk assessment of mixtures. Risk assessment of chemicals has traditionally focused on the effects of individual chemical exposures. Currently, risk assessment of chemicals, including pesticides, is based on the no observed adverse effect levels (NOAELs) for effects of single compounds. Based on results from animal studies, exposure to single environmental chemicals generally does not cause major concern for adverse reproductive effects in humans due to low exposure levels. Humans are, however, exposed to a mixture of several chemicals and, during the past decade, scientific and regulatory focus has gradually begun shifting towards examining the effects of mixtures. Since 2005, the European Union member states have for example been obliged to evaluate and, if possible, refine existing methodologies in order to take combined actions of pesticides into account during risk assessment and, especially, when establishing maximum residue levels for pesticides (European Commission, 2005). Due to the high number of possible chemical combinations, the option of basing human risk assessment of mixtures on experimental data of each possible chemical combination is not practically feasible. Therefore, development of new approaches is needed for handling the challenge of human risk assessment of mixtures.
The European Food Safety Authority (EFSA) has just released the report, "International Framework Dealing with Human Risk Assessment of Combined Exposure to Multiple Chemicals" presenting considerations on how to evaluate and handle mixture effects (European Food Safety Authority, 2013). The current thinking is that human risk for mixture exposure can be predicted by selecting a reasonable mathematical model (like the concentration-addition model (Hermens et al., 1984; Konemann, 1981)), and quantitative measures of toxic effects (e.g., NOAEL), as well as exposure levels for the individual chemicals (Kortenkamp et al., 2009; Hass et al., 2007; Hadrup et al., 2013). Based on this line of thought, one future challenge in risk assessment of mixtures is potentially lack of sufficient homogenous toxicological information on single compounds and their mechanisms of action. A second challenge for the toxicologist is the exponentially growing information load on chemicals in scientific databases, which poses the challenge of how to digest and utilize all existing information. A third challenge is how to predict adverse effects in humans based on toxicological information usually obtained from other species.

A potential solution to some of these challenges may be the application of systems toxicology. Systems toxicology has previously been employed as a means to explore potential adverse effects of environmental chemicals (Audouze and Grandjean, 2011). One of the strengths of the procedure is that focus can be directed exclusively towards human effects, avoiding the challenge of inter-species extrapolation.

In this paper, we present an evaluation of the procedure for grouping of chemicals according to their effects and modes of

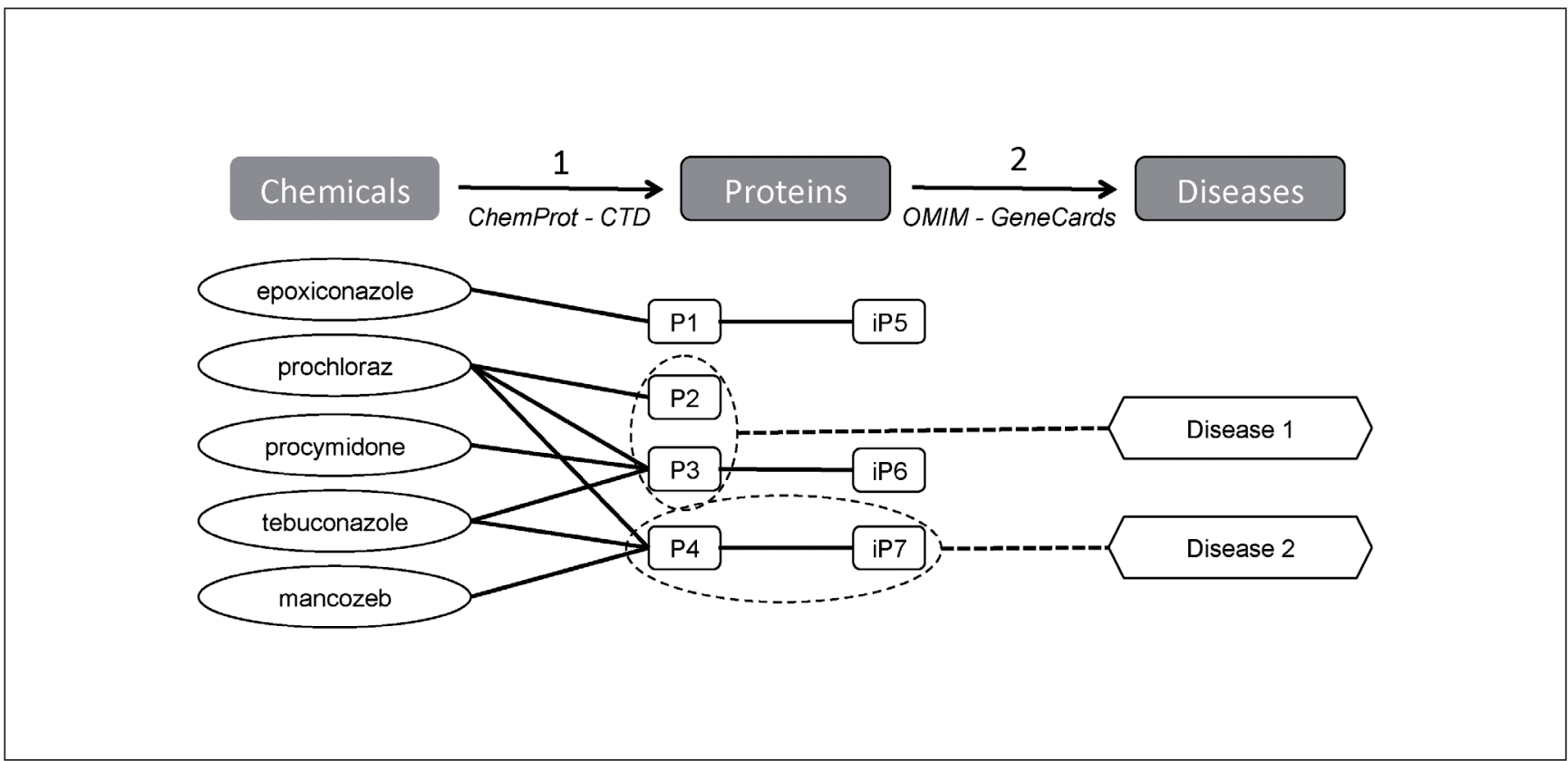

Fig. 1: Workflow of the proposed multi-step systems chemical biology approach

1. Proteins (P) known to be biologically associated with the five chemicals are extracted using two different databases (ChemProt and CTD). For each chemical, the set of proteins has been enriched with high confidence human protein-protein interaction data (iP).

2. Integration of disease information using three databases (GeneCards, OMIM, and a specific dataset related to male infertility) to each of the protein complexes. Diseases are statistically ranked to help link the chemicals to potential phenotypic outcomes. 
action that may be of benefit for a mixture risk assessment of chemicals for which homogenous toxicological information is lacking. We investigated the effects of five pesticides using a recently developed systems toxicology approach. This study served multiple purposes: 1) to apply systems toxicology to investigate modes of action of individual chemicals, 2) to explore the value of the approach for grouping of chemicals according to their mode of action, and 3) to hypothesize on new, unexpected effects of the chemicals in humans.

\section{Methods}

Procymidone, mancozeb, and the azole fungicides epoxiconazole, prochloraz, and tebuconazole were investigated using the multi-step data integration workflow (Fig. 1). In the first step, we used existing knowledge from disease chemical biology databases to extract information on specific human chemicalprotein associations. We queried for associations of the selected chemicals with genes and/or proteins in several sources of experimental data. Secondly, these chemical-protein associations were expanded to protein complexes. By using a high-confidence set of experimental protein-protein interactions, we identified protein complexes associated with the chemicals (Lage et al., 2007). Finally, protein-disease annotations were integrated into these protein complexes in order to statistically rank the chemicals' relation with diseases.

\section{Chemical-protein associations}

The first step was to extract available information for the five chemicals of interest. Only human related data was taken into consideration. Known chemical-protein associations were compiled from two publicly available databases, the Comparative Toxicogenomics Database (CTD) (Davis et al., 2011) and ChemProt 2.0 (Kim Kjærulff et al., 2013), accessed on October $8,2012)$. The CTD is a database of manually curated chemical-gene associations mined from peer-reviewed scientific literature. The Batch Query search method was used with default settings, searching for curated chemical-gene interactions using each chemical as input. ChemProt 2.0 is a newly established disease chemical biology database containing chemical-protein annotation resources for more than 1,100,000 unique chemicals and more than 15,000 proteins.

\section{Protein-protein interactions}

As proteins tend to function in protein complexes, we expanded each of the five obtained protein lists to contain known proteinprotein interactions (PPIs). We used a high confidence human protein interactome (Lage et al., 2007) (version 3.0), which is based on experimental data from humans and data inferred from model organisms. The version that was used (3.0) contains 507,142 unique PPIs and 22,997 genes, as of October 2012. The protein-protein interaction network used for our analyses is a scored network relying on network topology and reliability of each individual interaction. For further details on the construction and application of the protein-protein interaction network, please see Lage et al. $(2007,2008,2010)$. The human protein interactome was used to expand the initial networks by adding to the network proteins known to physically interact with the genes/proteins from the initial network.

\section{Disease enrichment}

To identify diseases possibly related to each individual chemical, we integrated disease information from three sources in each of the five protein complexes. The Online Mendelian Inheritance in Man (OMIM) database (McKusick-Nathans Institute of Genetic Medicine), the GeneCards database (Safran et al., 2010), and a specific dataset related to male infertility based on a review (Matzuk and Lamb, 2008) were used for data integration. The OMIM database is a comprehensive compendium of relationships between human genotypes and phenotypes. GeneCards is a searchable, integrated database providing information on human genes and selected gene-related information, such as functional and disease information.

The protein complexes for each of the five chemicals were individually tested for significant disease associations using a test based on a hypergeometric distribution. A significance level of 0.05 after Bonferroni correction for multiple testing of $p$-values was used to select the most relevant associations. The gene list for prochloraz is used here as an example in the test for an association with the disease adrenal hyperplasia: 46 out of 6778 genes in the GeneCards database were associated with the disease, and of the 27 genes associated with prochloraz, 10 were associated with the disease. This gave a $p$-value of $5.7 \mathrm{e}-16$, and the Bonferroni corrected $p$-value, when accounting for 10,428 diseases in the database, was $5.9 \mathrm{e}-12$, which is below the chosen significance level of 0.05 .

To investigate unexpected chemical-disease associations, we included non-significant associations for chemicals if the disease in question was significantly associated with at least one other chemical.

\section{Results}

\section{Protein lists}

Using the ChemProt 2.0 and CTD databases, we extracted one relevant human protein target for epoxiconazole, 22 for prochloraz, 5 for procymidone, 8 for tebuconazole, and 11 for mancozeb (Fig. 2). As 7 of the genes are shared between two or more of the chemicals, the complete gene list contains 38 different genes. Figure 3 shows a unified view of the respective associations. This figure demonstrates that there are a few shared gene associations for the chemicals. The androgen receptor (AR) is a shared target for prochloraz, procymidone, and tebuconazole. The cytochrome P450 (CYP) enzyme lanosterol-14$\alpha$-demethylase (CYP51A1) is a shared target for all three azole fungicides in accordance with their desired mechanism of action as fungicides. Prochloraz affects many proteins in the steroidogenic pathway and only CYP19A1 is a shared target with tebuconazole. Also, peroxisome proliferator-activated receptor $\delta$ (PPAR $\delta$ ) is a common target for prochloraz and tebuconazole, and PPAR $\delta$ is affected by prochloraz. In particular, mancozeb appears to have very distinct associations compared with the 


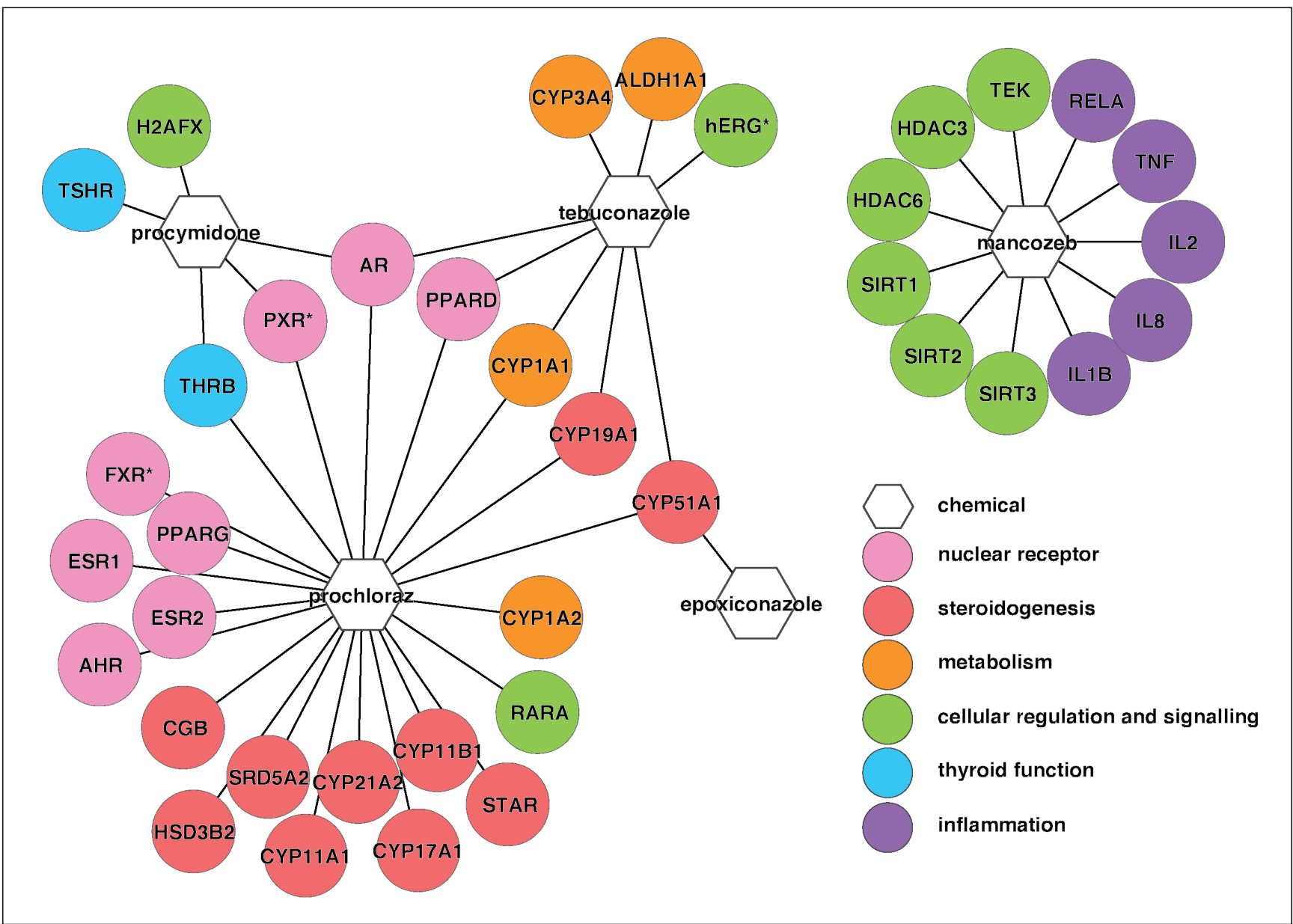

Fig. 2: Chemical-protein association network

Network view of the five chemicals and their associated genes denoted by HUGO gene symbol. Asterisks $\left(^{*}\right)$ indicate that the notation refers to the gene product rather than the gene itself. The colors of the genes correlate with primary function of the protein encoded by the genes. Red: transcription factor, orange: steroidogenesis, yellow: metabolism, green: cellular regulation and signaling, blue: thyroid function, and purple: inflammation. Chemicals are denoted as white hexagons. Mancozeb does not share any associations with the four other chemicals, and only a few genes connect the remaining chemicals.

remaining four chemicals. It targets mainly proteins involved in inflammatory and transcriptional processes. The thyroid receptor (THRB) is suggested as a target of both procymidone and prochloraz, whereas only procymidone affects the thyroidstimulating-hormone receptor (TSHR).

\section{Protein-protein interactions}

For each chemical we generated individual PPI networks by determining PPI partners for the proteins associated with the chemicals. To assess overlapping proteins, we generated a merged network. In this network, the chemicals were connected to their respective associated proteins retrieved from the initial step. The PPI networks were then viewed simultaneously (see Fig. S1 in supplementary data at http://www.altex-edition.org). As shown in Table 1, no proteins were identified in the epoxiconazole network, 81 in the prochloraz network, 18 in the procymidone network, 31 in the mancozeb network, and 25 in the tebuconazole network. This adds up to a total of 142 different
Tab. 1: Number of human proteins associated with the five chemicals within the different steps of the systems biology procedure

Numbers in parentheses indicate the number of connections between proteins in the network.

\begin{tabular}{|l|c|l|}
\hline \multirow{2}{*}{ Chemical name } & \multicolumn{2}{|l|}{ Number of proteins } \\
\cline { 2 - 3 } & $\begin{array}{l}\text { ChemProt, } \\
\text { CTD }\end{array}$ & $\begin{array}{l}\text { Proteins } \\
\text { (connections) }\end{array}$ \\
\hline Epoxiconazole & 1 & $1(0)$ \\
\hline Prochloraz & 22 & $81(123)$ \\
\hline Procymidone & 5 & $18(16)$ \\
\hline Mancozeb & 11 & $31(28)$ \\
\hline Tebuconazole & 8 & $25(22)$ \\
\hline Mixture & 38 & 142 \\
\hline
\end{tabular}




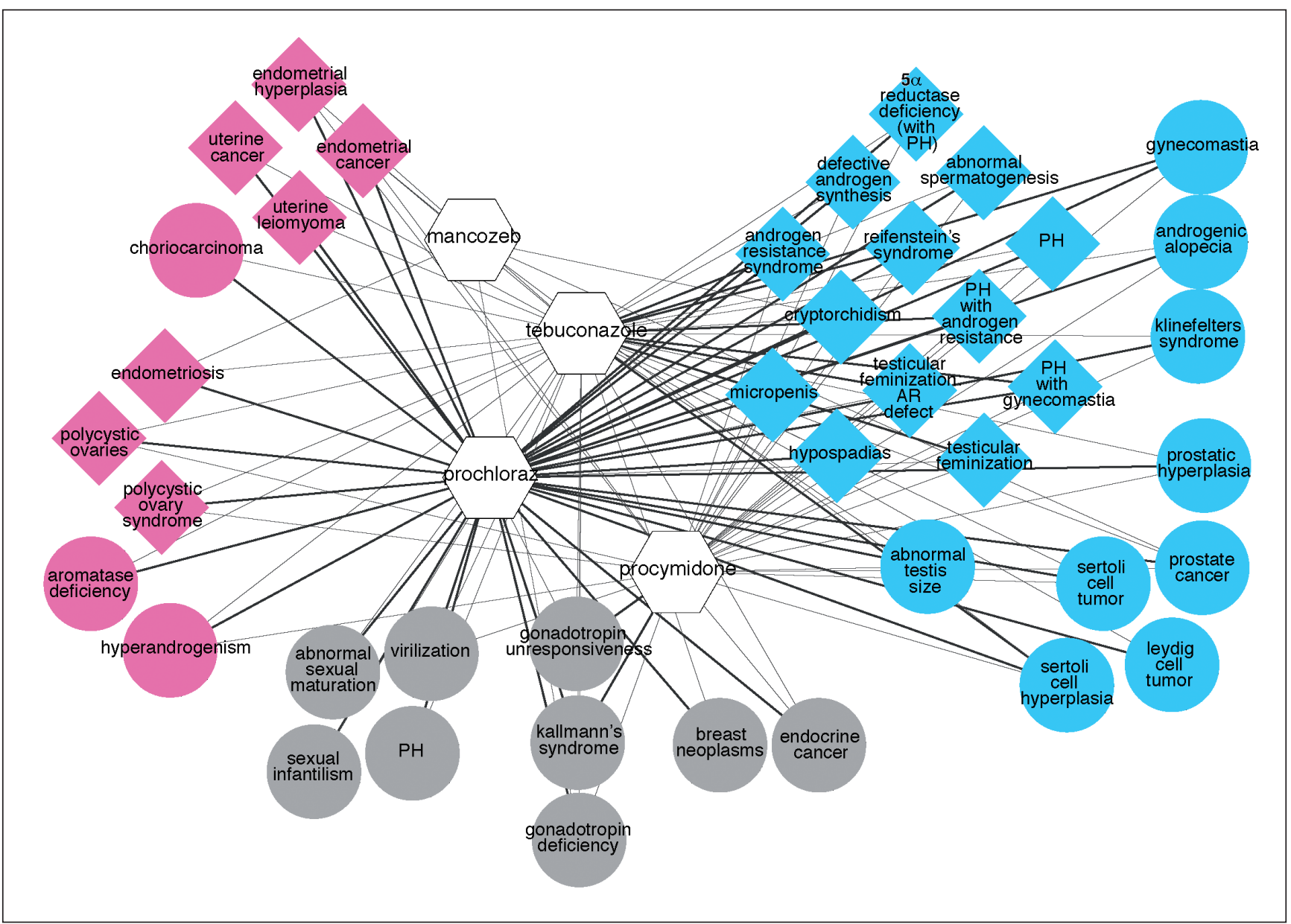

Fig. 3: Network showing the reproductive diseases that are associated with the four chemicals

The chemicals are the white hexagons, whereas female reproductive diseases are pink, male reproductive diseases are blue, and diseases affecting both genders or unclear phenotypes are grey. Blue diamonds indicate diseases that may be involved in testicular dysgenesis syndrome (TDS), whereas red diamonds indicate diseases that may be involved in ovarian dysgenesis syndrome (ODS). Black lines indicate significant ( $p$-value $\leq 0.05$ ) associations, whereas grey lines indicate non-significant associations $(p$-values $\geq 0.05$ ). $\mathrm{PH}$, pseudo hermaphroditism; AR, androgen receptor

proteins. The sub-network associated with mancozeb is completely isolated from other protein complexes. Considering the above results, epoxiconazole was not included in further calculations.

\section{Translation into disease associations}

To identify diseases associated with the individual chemicals, each PPI network was enriched using OMIM, GeneCards, and the male infertility dataset. This procedure provides indications of which chemicals might be associated with human disease(s). Instead of looking exclusively at statistically significant diseases, we increased the number of associations by including nonsignificant associations between diseases and chemicals if the disease in question was retrieved on the basis of a low p-value for at least one other chemical out of the five. One such example is the association between the chemicals and the disease term "micropenis". Prochloraz is the only chemical significantly associated with this disease term with a $p$-value corrected for multiple testing of 0.002 . Among the 81 proteins in the prochloraz network, only 41 were found in the GeneCards database. Among these 41 proteins, 5 were known to be associated with the disease "micropenis" as compared to a total of 9 known genes involved in the disease out of 5515 genes in the database. Tebuconazole and procymidone also showed associations with the condition "micropenis", however these associations were both non-significant due to the low number of associated genes. Despite the lack of significance, the association was extracted for further analyses to indicate potential associations with hypothetical adverse outcome pathways.

Three clusters of diseases appeared: One containing 41 reproductive diseases, a second one with seven disorders related to the adrenal gland, and a last one of six other diseases including adenoma, Antley-Bixler syndrome, Cushing syndrome, granulosa cell tumor, isolated deficiency of pituitary hormone, and xanthomatosis cerebrotendinous (see Fig. S2 in supplementary data at http://www.altex-edition.org). 
The large cluster of reproductive disorders was divided into three sub-clusters: male, female, and unisex (Fig. 3). The male sub-group contains 20 diseases. Among them, 13 seem to be associated with testicular dysgenesis syndrome (TDS), which covers a range of male reproductive diseases or disorders like malformed reproductive organs, cryptorchidism, poor sperm quality, and testicular cancer. These disorders are believed to reflect various stages of TDS arising during gestation (Skakkebaek et al., 2001). The 13 disorders covered by this analysis included androgen insensitivity syndrome, various types of pseudohermaphroditism, malformed or wrongly positioned testes, malformations of the penis including hypospadias, and underlying mechanisms for these disorders, such as androgen resistance syndrome and defective biosynthesis of testicular androgen. Additionally, various types of hyperplasia and prostate disease, and the terms gynecomastia, androgenic alopecia, Klinefelters syndrome, and abnormal testis size are associated with one or more of the chemicals through the chemical-gene associations (Fig. 3 and Tab. 2).

The female sub-cluster contains 10 diseases, of which seven diseases are associated with the ovarian dysgenesis syndrome (ODS), a recently suggested hypothesis parallel to the TDS paradigm, suggesting a shared etiology for endometriosis, ovarian cancers, and other diseases related to female fecundity (Louis et al., 2011). In this cluster, three subgroups of diseases exist: 1) disease terms related to various cancers within the female reproductive system, 2) polycystic ovaries and endometriosis, and 3 ) diseases related to abnormal hormone levels. All of these diseases are significantly associated with prochloraz and none of the other investigated chemicals. $P$-values after Bonferroni correction for multiple testing and the genes describing the chemical-disease associations are summarized in Table 2.

Tab. 2: Diseases extracted for the respective chemicals

The diseases are grouped according to gender specificity. Bonferroni corrected $p$-values and the genes associated with the diseases and involved in the respective diseases are listed by HUGO gene symbol. Statistically significant $p$-values are shown in bold format. N/A values indicate lack of associations. N/S indicates Bonferroni corrected $p$-values $\geq 1$.

\begin{tabular}{|c|c|c|c|c|c|c|c|c|c|}
\hline & \multirow[b]{2}{*}{ disease } & \multicolumn{2}{|l|}{ prochloraz } & \multicolumn{2}{|c|}{ procymidone } & \multicolumn{2}{|c|}{ tebuconazole } & \multicolumn{2}{|c|}{ mancozeb } \\
\hline & & Genes & $\begin{array}{l}\text { bonf. } \\
p \text {-val }\end{array}$ & genes & $\begin{array}{l}\text { bonf. } \\
p \text {-val }\end{array}$ & genes & $\begin{array}{l}\text { bonf. } \\
p \text {-val }\end{array}$ & genes & $\begin{array}{l}\text { bonf. } \\
p \text {-val }\end{array}$ \\
\hline \multirow[t]{9}{*}{ Male } & gynecomastia & $\begin{array}{l}\text { CGB; CYP17A1; CYP19A1; } \\
\text { CYP21A2; ESR1; HSD3B1; } \\
\text { HSD3B2; HSD17B3; AR; } \\
\text { SRD5A2 }\end{array}$ & 5.E-11 & AR & 0.79 & CYP19A1; AR & 0.03 & NONE & $\mathrm{N} / \mathrm{A}$ \\
\hline & hypospadias & $\begin{array}{l}\text { CYP1A1; CYP17A1; CYP21A2; } \\
\text { ESR1; ESR2; HSD3B1; } \\
\text { HSD3B2; HSD17B3; AR; } \\
\text { SRD5A2 }\end{array}$ & 4.E-08 & AR & $\mathrm{N} / \mathrm{S}$ & AR & $\mathrm{N} / \mathrm{S}$ & NONE & $\mathrm{N} / \mathrm{A}$ \\
\hline & $\begin{array}{l}\text { PH with } \\
\text { gynecomastia }\end{array}$ & $\begin{array}{l}\text { CYP19A1; HSD3B2; } \\
\text { HSD17B3; AR; SRD5A2 }\end{array}$ & 5.E-08 & AR & $N / S$ & CYP19A1; AR & 0.01 & NONE & $\mathrm{N} / \mathrm{A}$ \\
\hline & $\begin{array}{l}\mathrm{PH} \text { with } \\
\text { androgen } \\
\text { resistance }\end{array}$ & $\begin{array}{l}\text { CYP11B1; CYP19A1; } \\
\text { HSD3B2; AR }\end{array}$ & 3.E-05 & AR & N/S & CYP19A1; AR & 0.02 & NONE & $\mathrm{N} / \mathrm{A}$ \\
\hline & $\begin{array}{l}\text { reifenstein's } \\
\text { syndrome }\end{array}$ & $\begin{array}{l}\text { CYP11B1; CYP19A1; } \\
\text { HSD3B2; AR }\end{array}$ & 3.E-05 & AR & $N / S$ & CYP19A1; AR & 0.02 & NONE & $\mathrm{N} / \mathrm{A}$ \\
\hline & $\begin{array}{l}\text { leydig cell } \\
\text { tumor }\end{array}$ & $\begin{array}{l}\text { CYP11A1; CYP17A1; CYP19A1; } \\
\text { CYP21A2; ESR1; ESR2; } \\
\text { STAR }\end{array}$ & 9.E-05 & NONE & $\mathrm{N} / \mathrm{A}$ & CYP19A1 & N/S & NONE & $\mathrm{N} / \mathrm{A}$ \\
\hline & $\begin{array}{l}5 \text { a reductase } \\
\text { deficiency } \\
\text { (with } \mathrm{PH} \text { ) }\end{array}$ & HSD17B3; AR; SRD5A2 & 1.E-04 & AR & 0.63 & AR & $N / S$ & NONE & $\mathrm{N} / \mathrm{A}$ \\
\hline & $\mathrm{PH}$ & $\begin{array}{l}\text { CYP17A1; HSD3B2; HSD17B3; } \\
\text { AR; SRD5A2 }\end{array}$ & 3.E-04 & AR & N/S & AR & N/S & NONE & $\mathrm{N} / \mathrm{A}$ \\
\hline & $\begin{array}{l}\text { prostate } \\
\text { cancer }\end{array}$ & $\begin{array}{l}\text { CGB; CYP1A1; CYP1A2; CYP11 } \\
\text { CYP17A1; CYP19A1; AHR; ESR1 } \\
\text { ESR2; SPDEF; HSD3B1; } \\
\text { HSD3B2; HSD17B3; AR; PPARD } \\
\text { PPARG; PMEPA1; RARA; } \\
\text { SRD5A2; NR112; EBAG9 }\end{array}$ & $\begin{array}{l}\text { A1; } \\
\text { D; } \\
\text { 1.E-03 }\end{array}$ & $\begin{array}{l}\text { SPDEF; } \\
\text { AR; PMEPA1 }\end{array}$ & $N / S$ & $\begin{array}{l}\text { CYP1A1; } \\
\text { CYP3A4; } \\
\text { CYP19A1; } \\
\text { SPDEF; AR; } \\
\text { KCNH2; } \\
\text { PPARD; } \\
\text { PMEPA1 }\end{array}$ & $N / S$ & $\begin{array}{l}\text { ANGPT2; } \\
\text { RELA; TEK }\end{array}$ & $\mathrm{N} / \mathrm{S}$ \\
\hline
\end{tabular}




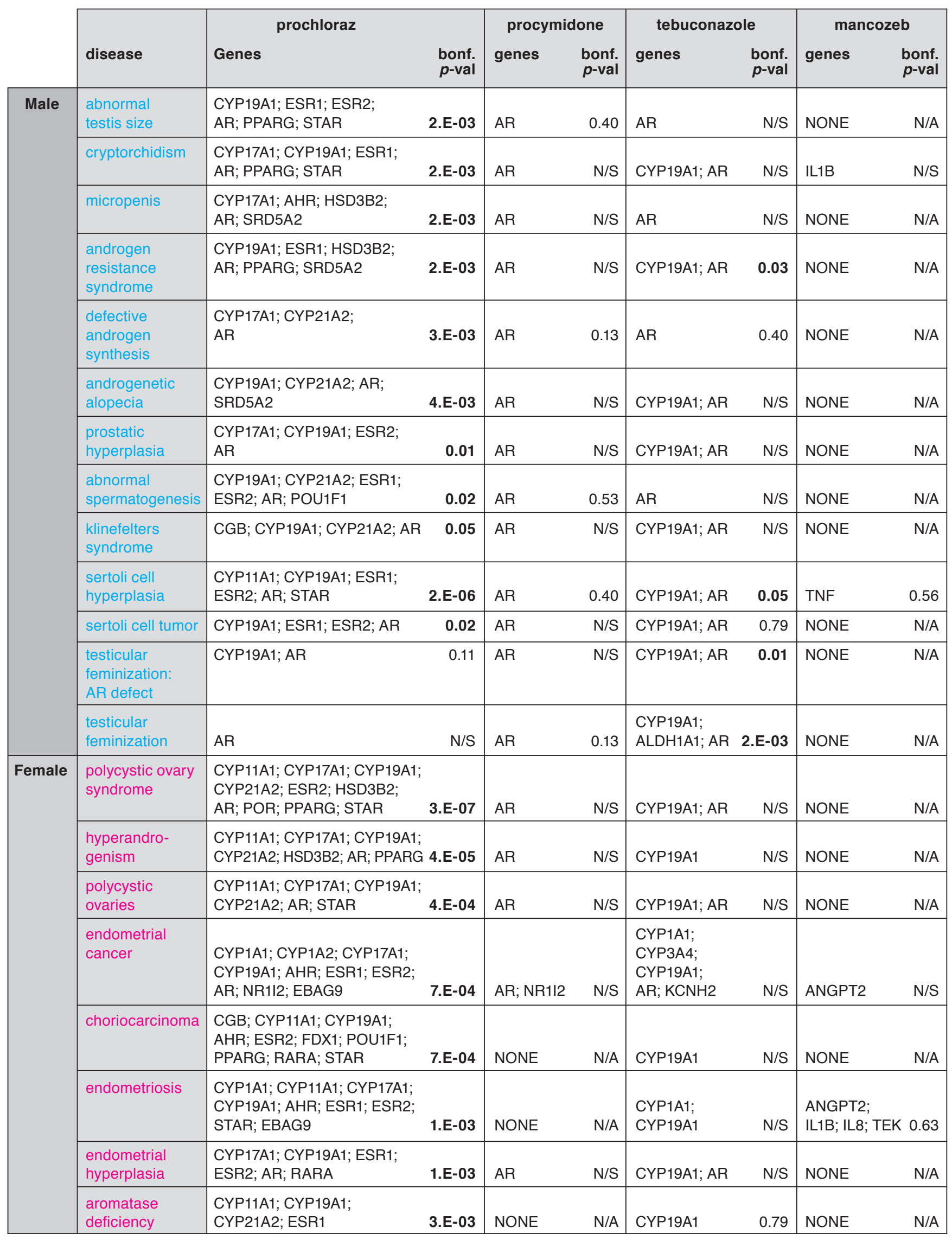




\begin{tabular}{|c|c|c|c|c|c|c|c|c|c|}
\hline & \multirow[b]{2}{*}{ disease } & \multicolumn{2}{|l|}{ prochloraz } & \multicolumn{2}{|c|}{ procymidone } & \multicolumn{2}{|c|}{ tebuconazole } & \multicolumn{2}{|c|}{ mancozeb } \\
\hline & & Genes & $\begin{array}{l}\text { bonf. } \\
p \text {-val }\end{array}$ & genes & $\begin{array}{l}\text { bonf. } \\
p \text {-val }\end{array}$ & genes & $\begin{array}{l}\text { bonf. } \\
p \text {-val }\end{array}$ & genes & $\begin{array}{l}\text { bonf. } \\
p \text {-val }\end{array}$ \\
\hline \multirow[t]{2}{*}{ Female } & $\begin{array}{l}\text { uterine } \\
\text { leiomyoma }\end{array}$ & $\begin{array}{l}\text { CYP17A1; CYP19A1; } \\
\text { CYP21A2; ESR1; ESR2 }\end{array}$ & 0.03 & NONE & $\mathrm{N} / \mathrm{A}$ & CYP19A1 & $\mathrm{N} / \mathrm{S}$ & NONE & $\mathrm{N} / \mathrm{A}$ \\
\hline & uterine cancer & CYP19A1; ESR1; ESR2 & 0.04 & NONE & $\mathrm{N} / \mathrm{A}$ & CYP19A1 & $N / S$ & NONE & $N / A$ \\
\hline \multirow[t]{9}{*}{ Unisex } & virilization & $\begin{array}{l}\text { CYP11A1; CYP11B1; CYP17A1; } \\
\text { CYP19A1; CYP21A2; HSD3B2; } \\
\text { AR; POR; SRD5A2 }\end{array}$ & 2.E-10 & $A R$ & $N / S$ & CYP19A1; AR & $N / S$ & NONE & N/A \\
\hline & $\begin{array}{l}\text { kallmann's } \\
\text { syndrome }\end{array}$ & $\begin{array}{l}\text { CYP19A1; CYP21A2; ESR1; } \\
\text { AR; POU1F1; PPARG; STAR; } \\
\text { THRB }\end{array}$ & 4.E-05 & $\begin{array}{l}\text { AR; THRB; } \\
\text { TSHB }\end{array}$ & 0.03 & CYP19A1; AR & $N / S$ & NONE & N/A \\
\hline & $\mathrm{PH}$ & $\begin{array}{l}\text { CYP17A1; CYP19A1; } \\
\text { HSD3B2; SRD5A2 }\end{array}$ & 3.E-04 & NONE & $\mathrm{N} / \mathrm{A}$ & CYP19A1 & $\mathrm{N} / \mathrm{S}$ & NONE & N/A \\
\hline & $\begin{array}{l}\text { gonadotropin } \\
\text { deficiency }\end{array}$ & $\begin{array}{l}\text { CYP19A1; ESR1; AR; } \\
\text { POU1F1; STAR }\end{array}$ & 2.E-03 & AR; TSHB & 0.17 & CYP19A1; AR & 0.47 & IL1B & $\mathrm{N} / \mathrm{S}$ \\
\hline & $\begin{array}{l}\text { breast } \\
\text { neoplasms }\end{array}$ & $\begin{array}{l}\text { CYP19A1; ESR1; } \\
\text { ESR2 }\end{array}$ & 7.E-03 & NONE & $\mathrm{N} / \mathrm{A}$ & CYP19A1 & $N / S$ & NONE & $N / A$ \\
\hline & sexual infantilism & CYP17A1; CYP19A1 & 0.01 & NONE & N/A & CYP19A1 & 0.40 & NONE & $\mathrm{N} / \mathrm{A}$ \\
\hline & $\begin{array}{l}\text { abnormal sexual } \\
\text { maturation }\end{array}$ & $\begin{array}{l}\text { CYP17A1; CYP19A1; CYP21A2; } \\
\text { ESR1 }\end{array}$ & 0.01 & NONE & N/A & CYP19A1 & N/S & NONE & N/A \\
\hline & $\begin{array}{l}\text { endocrine } \\
\text { cancer }\end{array}$ & CYP19A1; ESR1; AR & 0.01 & AR & $\mathrm{N} / \mathrm{S}$ & CYP19A1; AR & 0.23 & NONE & N/A \\
\hline & $\begin{array}{l}\text { gonadotropin un- } \\
\text { responsiveness }\end{array}$ & AR & $N / S$ & $\begin{array}{l}\text { AR; } \\
\text { TSHR }\end{array}$ & 2.E-03 & AR & $\mathrm{N} / \mathrm{S}$ & NONE & $\mathrm{N} / \mathrm{A}$ \\
\hline
\end{tabular}

\section{Discussion}

Due to recent advances in toxicogenomics, the existence of high confidence PPIs, and various types of "omics" information, a reasonable basis for developing models to predict associations between chemical exposures and subsequent human health effects has arisen.

We retrieved a set of genes linked to the query chemicals and these chemical-gene associations, reported in experimental studies, constitute the raw data. This method constitutes an efficient means for retrieval of known information compared to manual search in the published literature for chemical-gene/ protein associations. Such a manual literature search is feasible in less investigated areas but for well-investigated disorders and common chemicals obtaining such a literature overview manually is laborious. Thus, the current approach creates a valuable overview of existing data on the mechanisms of action of chemicals, allowing grouping of chemicals according to their mechanism of action. This will be helpful when predicting mixture effects. Furthermore, this approach provides a method that may contribute to developing candidate adverse outcome pathways. For chemicals that are known to cause similar adverse effects, applying this approach and thus setting up hypotheses on potential molecular initiating events for specific adverse effects can help elucidate similarities in mode of action of the chemicals (Ankley et al., 2010). However, since the data from the initial data sources may have been tested under complex conditions, there is a risk that the obtained gene lists contain false positives. CTD, as an example, contains data from microarray experiments and several biological factors are detrimental for gene expression levels. Hence, misregulation of genes is not always a direct response to chemicals affecting expression levels of genes but may be due to a stress condition of the exposed organism induced by the chemical, e.g., via disruption of the electron transport chain in mitochondria. The results of our study serve as a guideline, and careful interpretation is an essential part of the workflow as false positives might be present.

Furthermore, one must take into account the so-called "Matthew effect", resulting in maintained research interests regarding already well-investigated chemicals, effects, and/or targets, and thus a larger amount of available data for these chemicals and effects (Grandjean et al., 2011). This skews the findings towards pathways and diseases already being intensely investigated but also highlights the areas or chemicals needing further attention, like epoxiconazole in this study. The relatively high and low number of chemical-gene/protein associations for, e.g., prochloraz and epoxiconazole, respectively, may be a result of 
this effect, as the amount of available data for the two chemicals differs (by a factor of 2.7 based on a PubMed search in July 2013). Hence, the lack of associations between, e.g., epoxiconazole or procymidone and the diseases predicted to be associated with prochloraz might be the result of less available data for the chemicals rather than lack of effects.

For risk assessment of mixtures, it has been proposed that being able to group the chemicals according to their mechanism or mode of action might be a great advantage (Kortenkamp et al., 2009). Previously, we found that mixture effects can be predicted on the basis of endpoints of varying molecular complexity, such as anatomical, morphological, or genomic output (Metzdorff et al., 2007). In a comprehensive in vivo developmental rat study, additivity of some anti-androgenic chemicals was predicted irrespective of the level at which the adverse effects were seen; be it adverse morphological changes or changes in gene expression in the male reproductive organs. This finding supports the hypothesis that molecular data can be applied for predicting mixture effects (Metzdorff et al., 2007). Viewing the chemical-gene associations for all chemicals simultaneously provides an overview of chemicals that share pharmacological or toxicological targets. This is valuable information in cases where grouping of chemicals is needed. According to our results, mancozeb has a mode of action that is distinct from that of prochloraz, procymidone, and tebuconazole. The latter three, on the other hand, seem to share targets. Therefore, rough grouping of the five chemicals results in two groups, mancozeb alone, and the above-mentioned three chemicals together. Epoxiconazole, having a single gene association, is only vaguely grouped with prochloraz, procymidone, and tebuconazole via its association with CYP51. This is most likely due to lack of data for this chemical.

The results presented in Figure 3 (and Fig. S2) indicate involvement of the chemicals in human diseases related to reproductive disorders. Prochloraz has the highest number of significant disease associations compared to the other chemicals. The disorders affected by this chemical have both masculinizing effects in females and feminizing effects in males. Several findings in the literature support the feminizing effects in males suggested here. Prochloraz is the most widely studied chemical and has been demonstrated to affect fetal rat testes, resulting in disrupted steroidogenesis during prenatal development (Laier et al., 2006). The mechanism underlying this disruption includes inhibition of the cytochrome P450 enzymes CYP17 and CYP19 (Andersen et al., 2002). Prochloraz has been demonstrated to be associated with decreased estradiol and testosterone production, increased progesterone production, and aromatase inhibition in vitro (Dreisig et al., 2013). In several instances it has been demonstrated that chemicals having such an in vitro profile cause feminizing effects, such as decreased nipple retention and decreased anogenital distance in vivo. This has been demonstrated for prochloraz exposure during fetal development (Vinggaard et al., 2005). The predicted involvement of prochloraz in TDS (cryptorchidism, hypospadias, poor sperm quality, and carcinoma in situ testis) is of particular concern. In the past four decades the incidence of male reproductive disorders has increased, and to a larger extent in developed and industrialized countries compared to developing countries (Giwercman et al., 1993; Skakkebaek et al., 2001; Jorgensen et al., 2006). It has been suggested that occupational exposure to pesticides contributes to the increased incidence of male reproductive disorders, including TDS (Weidner et al., 1998). Similarly, a recent paper suggested that prenatal exposure of human male fetuses to various non-persistent pesticides was associated with smaller genitals in boys aged 6-11 years compared to boys without prenatal pesticide exposure (Wohlfahrt-Veje et al., 2012). Furthermore, the results also point to an association between exposure to prochloraz and female reproductive diseases, including diseases of ODS. Previous studies have indicated the existence of a causal relationship between exposure to (organochlorine) pesticides and the development of endometriosis (Porpora et al., 2009; Cooney et al., 2010). Together, these findings point towards the importance of investigating female reproductive effects as well.

The findings of prochloraz on feminizing and masculinizing effects are paralleled by tebuconazole, although less pronounced. According to the results presented in Figure 3, tebuconazole has five significant disease associations in common with prochloraz. It is known that tebuconazole has a mode of action like prochloraz, as both affect sex hormone synthesis (Dreisig et al., 2013; Kjaerstad et al., 2010).

Procymidone has one significant disease association in common with prochloraz (Kallmann's syndrome, $p$-values $2.53 \mathrm{e}-2$ and $4.21 \mathrm{e}-5$, respectively). Despite the few significant associations, it is reasonable to infer a possible association with reproductive dysfunction, since procymidone acts as an antagonist of the androgen receptor. This is known from in vitro and in vivo experiments (Ostby et al., 1999; Hosokawa et al., 1993; Nellemann et al., 2003) that reported cryptorchidism (Wolf et al., 1999), decreased anogenital distance, and decreased nipple retention in prenatally exposed rats (Hass et al., 2012; Wolf et al., 1999).

Our data indicate that the effects of mancozeb are not a consequence of interference with human sex hormone synthesis or sex hormone receptor activity as opposed to the other chemicals investigated in this study. This is consistent with previous experimental work in rodents showing no effect of mancozeb on male reproductive endpoints (Axelstad et al., 2011). Mancozeb might, however, contribute to the manifestation of reproductive diseases through other mechanisms. It is established that mancozeb induces oxidative stress in rodent cells (Domico et al., 2007). Persistent oxidative stress might lead to inflammation, and this may be the reason why mancozeb, according to our model, is associated with several genes involved in inflammation. It is, however, surprising not to see any genes related to thyroid function, as animal studies in rodents indicate a strong relationship between exposure to mancozeb and decreased levels of the thyroid hormone $\mathrm{T}_{4}$ in dams and hence a possible role of mancozeb in thyroid disruption in humans (Axelstad et al., 2011). Species differences are not expected to explain why our model does not predict a link between mancozeb and thyroid function (US EPA, 2005). Since epidemiological studies have 
shown an association between human mancozeb exposure and diagnosed thyroid disease (Goldner et al., 2010; Steenland et al., 1997), the lack of associations between mancozeb and any thyroid-related genes in our study might be caused by a lack of thyroid tissue data in the queried databases. The epidemiological studies, however, do not provide a suggestion as to which proteins or genes are targeted by mancozeb. One alternative explanation might be that the thyroid effects are secondary to inflammatory changes.

Using this computational approach to assess the effect of chemicals provides an overview of which chemicals in a mixture might interfere with identical proteins, and which chemicals might result in similar disease phenotypes despite dissimilar modes of action. The method might prove useful if hypotheses on similar and dissimilar modes of action are needed to determine chemicals more prone to act on the same target and thus needing more attention. In addition, this methodology may prove valuable for generating hypotheses on the linkage between chemical exposure and human disease, providing knowledge on which chemicals to prioritize for further testing. This methodology provides a unique opportunity to get closer to the potential adverse effects on human health of chemicals.

\section{Conclusion}

We suggest that this computational technology is valuable for achieving an overview of existing targets related to a certain chemical. The value lies in the relevance for human health. Information about human health and exposure to environmental chemicals is rarely available, and exists as results from epidemiological studies, where several confounding factors might interfere with the measured endpoints. Therefore, this method opens up new possibilities for generation of hypotheses linking chemical exposure and human diseases.

Application of the method resulted in grouping of the three pesticides, prochloraz, tebuconazole, and procymidone. Male and female reproductive disorders like TDS and ODS and some adrenal diseases were primarily found to be associated with these pesticides. Epoxiconazole is expected to belong to this group, but lack of data did not allow this conclusion. Mancozeb had a differential mode of action involving inflammatory processes not shared by any of the other pesticides. These findings seem plausible based on comparisons with actual knowledge from cellular and rodent studies, giving confidence in the approach when less well-known chemicals are evaluated in the future.

\section{References}

Andersen, H. R., Vinggaard, A. M., Rasmussen, T. H., et al. (2002). Effects of currently used pesticides in assays for estrogenicity, androgenicity, and aromatase activity in vitro. Toxicol Appl Pharmacol 179, 1-12.
Ankley, G. T., Bennett, R. S., Erickson, R. J., et al. (2010). Adverse outcome pathways: a conceptual framework to support ecotoxicology research and risk assessment. Environ Toxicol Chem 29, 730-741.

Audouze, K. and Grandjean, P. (2011). Application of computational systems biology to explore environmental toxicity hazards. Environ Health Perspect 119, 1754-1759.

Axelstad, M., Boberg, J., Nellemann, C., et al. (2011). Exposure to the widely used fungicide mancozeb causes thyroid hormone disruption in rat dams but no behavioral effects in the offspring. Toxicol Sci 120,439-446.

Christiansen, S., Scholze, M., Axelstad, M., et al. (2008). Combined exposure to anti-androgens causes markedly increased frequencies of hypospadias in the rat. Int J Androl 31, 241248.

Christiansen, S., Scholze, M., Dalgaard, M., et al. (2009). Synergistic disruption of external male sex organ development by a mixture of four antiandrogens. Environ Health Perspect 117, 1839-1846.

Cooney, M. A., Buck Louis, G. M., Hediger, M. L., et al . (2010). Organochlorine pesticides and endometriosis. Reprod Toxicol 30, 365-369.

Damgaard, I. N., Skakkebaek, N. E., Toppari, J., et al. (2006). Persistent pesticides in human breast milk and cryptorchidism. Environ Health Perspect 114, 1133-1138.

Davis, A. P., King, B. L., Mockus, S., et al. (2011). The Comparative Toxicogenomics Database: update 2011. Nucleic Acids Res 39, D1067-D1072.

Domico, L. M., Cooper, K. R., Bernard, L. P., et al. (2007). Reactive oxygen species generation by the ethylene-bis-dithiocarbamate (EBDC) fungicide mancozeb and its contribution to neuronal toxicity in mesencephalic cells. Neurotoxicology 28, 1079-1091.

Dreisig, K., Taxvig, C., Birkhoj Kjaerstad, M., et al. (2013). Predictive value of cell assays for developmental toxicity and embryotoxicity of conazole fungicides. ALTEX 30, 319-330.

EC - European Commision (2005). Regulation (EC) No 396/2005 of the European Parliament and of the Council of 23 February 2005 on maximum residue levels of pesticides in or on food and feed of plant and animal origin and amending Council Directive 91/414/EECText with EEA relevance. $O f$ ficial J EU 396/2005, 1-16.

EFSA - European Food Safety Authority (2013). International framework dealing with human risk assessment of combined exposure to multiple chemicals. EFSA Journal 11, 1-69.

Giwercman, A., Carlsen, E., Keiding, N., et al. (1993). Evidence for increasing incidence of abnormalities of the human testis: a review. Environ Health Perspect 101, Suppl 2, 65-71.

Goldner, W. S., Sandler, D. P., Yu, F., et al. (2010). Pesticide use and thyroid disease among women in the Agricultural Health Study. Am J Epidemiol 171, 455-464.

Grandjean, P., Eriksen, M. L., Ellegaard, O., et al. (2011). The Matthew effect in environmental science publication: a bibliometric analysis of chemical substances in journal articles. Environ Health 10, 96. 
Hadrup, N., Taxvig, C., Pedersen, M., et al. (2013). Concentration addition, independent action and generalized concentration addition models for mixture effect prediction of sex hormone synthesis in vitro. PLoS One 8, e70490.

Hass, U., Scholze, M., Christiansen, S., et al. (2007). Combined exposure to anti-androgens exacerbates disruption of sexual differentiation in the rat. Environ Health Perspect 115, Suppl 1, 122-128.

Hass, U., Boberg, J., Christiansen, S., et al. (2012). Adverse effects on sexual development in rat offspring after low dose exposure to a mixture of endocrine disrupting pesticides. Reprod Toxicol 34, 261-274.

Hermens, J., Leeuwangh, P., and Musch, A. (1984). Quantitative structure-activity relationships and mixture toxicity studies of chloro- and alkylanilines at an acute lethal toxicity level to the guppy (Poecilia reticulata). Ecotoxicol Environ Safety 8, 388-394.

Hosokawa, S., Murakami, M., Ineyama, M., et al. (1993). The affinity of procymidone to androgen receptor in rats and mice. J Toxicol Sci 18, 83-93.

Jacobsen, P. R., Axelstad, M., Boberg, J., et al. (2012). Persistent developmental toxicity in rat offspring after low dose exposure to a mixture of endocrine disrupting pesticides. Reprod Toxicol 34, 237-250.

Jorgensen, N., Asklund, C., Carlsen, E., et al. (2006). Coordinated European investigations of semen quality: results from studies of Scandinavian young men is a matter of concern. Int $J$ Androl 29, 54-61; discussion 105-108.

Kim Kjærulff, S., Wich, L., Kringelum, J., et al. (2013). ChemProt-2.0: visual navigation in a disease chemical biology database. Nucleic Acids Res 41, D464-469.

Kjaerstad, M. B., Taxvig, C., Andersen, H. R., et al. (2010). Mixture effects of endocrine disrupting compounds in vitro. Int $J$ Androl 33, 425-433.

Knudsen, T., Martin, M., Chandler, K., et al. (2013). Predictive models and computational toxicology. Methods Mol Biol 947, 343-374.

Konemann, H. (1981). Fish toxicity tests with mixtures of more than two chemicals: a proposal for a quantitative approach and experimental results. Toxicology 19, 229-238.

Kortenkamp, A., Backhaus, T., and Faust, M. (2009). State of the Art Review of Mixture Toxicity. http://ec.europa.eu/environment/chemicals/effects/pdf/report_mixture_toxicity.pdf

Krysiak-Baltyn, K., Toppari, J., Skakkebaek, N. E., et al. (2010). Country-specific chemical signatures of persistent environmental compounds in breast milk. Int J Androl 33, 270-278.

Krysiak-Baltyn, K., Toppari, J., Skakkebaek, N. E., et al. (2012). Association between chemical pattern in breast milk and congenital cryptorchidism: modelling of complex human exposures. Int J Androl 35, 294-302.

Lage, K., Karlberg, E. O., Storling, Z. M., et al. (2007). A human phenome-interactome network of protein complexes implicated in genetic disorders. Nat Biotechnol 25, 309-316.

Lage, K., Hansen, N. T., Karlberg, E. O., et al. (2008). A largescale analysis of tissue-specific pathology and gene expres- sion of human disease genes and complexes. Proc Natl Acad Sci U S A 105, 20870-20875.

Lage, K., Mollgard, K., Greenway, S., et al. (2010). Dissecting spatio-temporal protein networks driving human heart development and related disorders. Mol Syst Biol 6, 381.

Laier, P., Metzdorff, S. B., Borch, J., et al. (2006). Mechanisms of action underlying the antiandrogenic effects of the fungicide prochloraz. Toxicol Appl Pharmacol 213, 160-171.

Louis, G. M. B., Cooney, M. A., and Peterson, C. M. (2011). The ovarian dysgenesis syndrome. J Dev Orig Health Dis 2, 25-35.

Matzuk, M. M. and Lamb, D. J. (2008). The biology of infertility: research advances and clinical challenges. Nature Med 14, 1197-1213.

Metzdorff, S. B., Dalgaard, M., Christiansen, S., et al. (2007). Dysgenesis and histological changes of genitals and perturbations of gene expression in male rats after in utero exposure to antiandrogen mixtures. Toxicol Sci 98, 87-98.

Nellemann, C., Dalgaard, M., Lam, H. R., et al. (2003). The combined effects of vinclozolin and procymidone do not deviate from expected additivity in vitro and in vivo. Toxicol Sci 71, 251-262.

Ostby, J., Kelce, W. R., Lambright, C., et al. (1999). The fungicide procymidone alters sexual differentiation in the male rat by acting as an androgen-receptor antagonist in vivo and in vitro. Toxicol Ind Health 15, 80-93.

Porpora, M. G., Medda, E., Abballe, A., et al. (2009). Endometriosis and organochlorinated environmental pollutants: a case-control study on Italian women of reproductive age. Environ Health Perspect 117, 1070-1075.

Rajapakse, N., Silva, E., and Kortenkamp, A. (2002). Combining xenoestrogens at levels below individual No-observedeffect concentrations dramatically enhances steroid hormone action. Environ Health Perspect 110, 917-921.

Safran, M., Dalah, I., Alexander, J., et al . (2010). GeneCards Version 3: the human gene integrator. Database 2010, baq020.

Silva, E., Rajapakse, N., and Kortenkamp, A. (2002). Something from "nothing" - eight weak estrogenic chemicals combined at concentrations below NOECs produce significant mixture effects. Environ Sci Technol 36, 1751-1756.

Skakkebaek, N. E., Rajpert-De Meyts, E., and Main, K. M. (2001). Testicular dysgenesis syndrome: an increasingly common developmental disorder with environmental aspects. Hum Reprod 16, 972-978.

Steenland, K., Cedillo, L., Tucker, J., et al. (1997). Thyroid hormones and cytogenetic outcomes in backpack sprayers using ethylenebis(dithiocarbamate) (EBDC) fungicides in Mexico. Environ Health Perspect 105, 1126-1130.

Swan, S. H., Kruse, R. L., Liu, F., et al. (2003). Semen quality in relation to biomarkers of pesticide exposure. Environ Health Perspect 111, 1478-1484.

Swan, S. H., Main, K. M., Liu, F., et al. (2005). Decrease in anogenital distance among male infants with prenatal phthalate exposure. Environ Health Perspect 113, 1056-1061.

US EPA (2005). EPA Mancozeb Facts. Prevention Pesticides 
and Toxic Substances. http://www.epa.gov/oppsrrd1/REDs/ factsheets/mancozeb_fact.pdf

Vinggaard, A. M., Christiansen, S., Laier, P., et al. (2005). Perinatal exposure to the fungicide prochloraz feminizes the male rat offspring. Toxicol Sci 85, 886-897.

Weidner, I. S., Moller, H., Jensen, T. K., et al. (1998). Cryptorchidism and hypospadias in sons of gardeners and farmers. Environ Health Perspect 106, 793-796.

Wohlfahrt-Veje, C., Boisen, K. A., Boas, M., et al. (2009). Acquired cryptorchidism is frequent in infancy and childhood. Int J Androl 32, 423-428.

Wohlfahrt-Veje, C., Andersen, H. R., Jensen, T. K., et al . (2012). Smaller genitals at school age in boys whose mothers were exposed to non-persistent pesticides in early pregnancy. Int $J$ Androl 35, 265-272.

Wolf, C., Jr., Lambright, C., Mann, P., et al. (1999). Administration of potentially antiandrogenic pesticides (procymidone, linuron, iprodione, chlozolinate, p,p'-DDE, and ketoconazole) and toxic substances (dibutyl- and diethylhexyl phthalate, PCB 169, and ethane dimethane sulphonate) during sexual differentiation produces diverse profiles of reproductive malformations in the male rat. Toxicol Ind Health 15, 94-118.

\section{Acknowledgements}

The Ministry of Food, Agriculture and Fisheries of Denmark and the Danish Veterinary and Food Administration are acknowledged for their financial support. The Villum Kann Rasmussen Foundation contributed financially to development of the systems toxicology approach.

\section{Financial interests declaration}

The authors declare they have no actual or potential competing financial interests.

\section{Correspondence address}

Kristine Kongsbak

Division of Toxicology and Risk Assessment, National Food Institute,

Technical University of Denmark

Mørkhøj Bygade 19

Building G, Room 118

2860 Søborg, Denmark

e-mail:kgko@food.dtu.dk 